\title{
Marketing library and information services: international perspectives (Gupta; Konntz; Massísimo; Savard)
}

\author{
Por Viviana Fernández Marcial
}

\begin{abstract}
Fernández Marcial, Viviana. "Marketing library and information services: international perspectives (Gupta; Konntz; Massísimo; Savard)”. Reseña. En: El profesional de la información, 2007, enero-febrero, v. 16, n. 1, pp. 82-83.
\end{abstract}

ESTA OBRA PUBLICADA BAJO el patrocinio de la IFLA, en particular de la Management and Marketing Section, recoge las experiencias en marketing bibliotecario desarrolladas en diferentes partes del mundo. El libro representa la tercera publicación centrada en este tema. El primer volumen fue editado bajo el título Adapting marketing to libraries in a changing and world-wide environment en 2000, al año siguiente se publicó la obra Education and research for marketing and quality management in libraries.

$\mathrm{Si}$ se hace referencia a este precedente es para significar la creciente importancia que va adquiriendo el tema. La primera de estas obras era apenas una escuálida publicación que si bien aportaba interesantes propuestas teóricas, en particular las reflexiones sobre la actitud de los bibliotecarios frente al marketing, carecía de textos sobre situaciones prácticas. La publicación siguiente supera esta deficiencia pero el incremento de los textos era consecuencia de que el marketing aparece unido a la gestión de la calidad.

Esta obra, sin dejar de ofrecer textos teóricos, brinda una vasta panorámica sobre la situación del marketing en las más diversas regiones. Una rápida revisión de las contribuciones permite confirmar que los países anglosajones poseen un mayor avance en cuanto a iniciativas teóricas y prácticas. Se hace notar también una alta participación de países de Europa del Este (Croacia, Rumania, Estonia, Lituania) y de Asia (China, Pakistán o India) lo que deja entrever ausencias notables como por ejemplo Portugal e Italia.

Conviene destacar, en primer lugar, las aportaciones que permiten conocer la historia y evolución del marketing en las bibliotecas. Gupta ofrece un interesante recorrido histórico que sitúa el nacimiento del marketing bibliotecario a finales de la década de los sesenta. Koontz describe una historia de la excelencia en el marketing, basado en la relación de los galardonados por el IFLA/3M Marketing Award. Angelica do Amaral realiza una revisión a la literatura sobre el marketing mix o las $4 \mathrm{P}$ a lo largo de dos décadas ${ }^{1}$.

La sección II, bajo el título Marketing libraries around the world, concentra gran parte de las experiencias. Sorprende gratamente las contribuciones de autores que expresan la realidad de China, África, Croacia y Pakistán. Nawe y Tanui, en diferentes textos, detallan una serie de actividades promocionales en bibliotecas africanas y coinciden que el marketing se encuentra en un estadio inicial. Tibljas describe la realidad de una biblioteca pública en Croacia que ha desarrollado el proyecto Teens for teens y que es un excelente ejemplo de que el concepto público objetivo no es contrario a la naturaleza de las bibliotecas.

Àngels Massísimo y José Antonio Gómez presentan la situación que nos podemos encontrar en España y sitúan los inicios a partir de una contribución de Lasso de Vega,

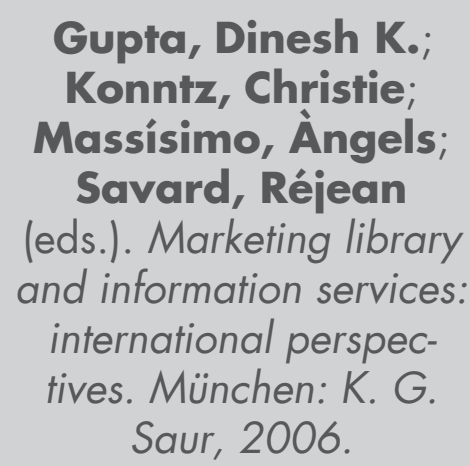

Gupta, Dinesh K.; Konntz, Christie; Massísimo, Àngels; Savard, Réjean (eds.). Marketing library and information services: international perspectives. München: K. G. Saur, 2006.

en 1946, aportando un balance de las principales actividades promocionales iniciadas en la década de los setenta, en particular describen las diferentes campañas desarrolladas en Cataluña, Castilla La Mancha y Murcia.

Muy interesantes resultan las aportaciones de Brewerton que expone el caso de la Oxford Brookes University Library y de Mohammed que refleja la experiencia de la Australian Islamic College. No en balde ambos ejemplos se encuentran en la sección V, Excellence in marketing. El primero es exhaustivo en datos y presenta una gestión sistémica y orgánica del marketing. El segundo describe un programa de marketing creado con una visión social en el que la biblioteca asume un rol activo en la integración y alfabetización de escolares de cultura islámica.

A largo de la obra persiste una idea: no es posible desarrollar acciones de marketing si no existe una cultura propicia en las bibliotecas. Bükkei y Király citan los diversos obstáculos que dificultan el uso de las técnicas de marketing en las 
bibliotecas de Rumanía, haciendo alusión a las "barreras mentales". Muet que hace referencia a la situación de Francia, destaca que bibliotecarios y documentalistas han estado más interesados en las labores de carácter técnico que en el marketing que se ha considerado como propio del ámbito empresarial.

En este sentido, la sección IV, Education, training and research, que aborda esencialmente la problemática de la formación, refleja una posibilidad de paliar esta situación. Sin embargo, las experiencias no muestran precisamente un panorama demasiado halagüeño. Los diversos autores coinciden en una idea que sintetiza Webber. La autora sostiene que es una disciplina aún pendiente de ocupar un "lugar prominente en los planes de los estudios universitarios de biblioteconomía y documentación".

Podría indicarse que la situación más positiva aparece en Norteamérica en los MLIS (Master in library and information science). Wiston sin embargo, señala que en estos programas el marketing se considera como un contenido dentro los módulos de gestión. Semejante panorama describe Webber para el caso del Reino Unido, quien apunta que mientras los contenidos de gestión están ampliamente contemplados en los programas de estudio, el marketing es una materia que no siempre aparece. Resulta llamativo que en países como Estonia, India, Pakistán aún de forma tímida sí los hay en los programas de biblioteconomía.

La publicación se divide en seis secciones y tiene como peculiaridad que, más allá de éstas, para poder abarcar un tema es necesario consultar varios apartados. Por ejemplo, la historia del marketing bibliotecario precisa examinar los textos de la sección I, Marketing concepts, la quinta y la última, $D a$ tabases and other marketing literatura. Esta última, un tanto miscelánea, tiene como uno de los textos más interesantes aquel que describe MatPromo, una base de datos de imágenes que sistematiza los medios de promoción utilizados en bibliotecas de varios países.

\section{http://bidoc.ub.es/pub/matpromo}

Si se toma esta obra como proyección de futuro se podrían señalar dos tendencias. Una más obvia: el aumento del interés por aplicar el marketing como sistema de gestión en las bibliotecas. La otra se deja entrever a lo largo de los textos: el uso cada vez mayor de encuestas, focus group, entrevistas y de métodos más específicos del marketing, como los estudios de mercado como vía para conocer y analizar la realidad.

La edición es cuidada y aun- que lamentablemente persiste la tendencia de obviar los índices de materia, el libro se vale de un breve texto introductorio en cada bloque que sintetiza lo más importante de éstos y que destaca, en ocasiones, por ser una imprescindible introducción a cada tema. Así, en la primera sección se ofrece una relación cronológica de los términos utilizados y sus autores; en la sección III, Rol of library associations, se brinda un cuadro donde se alude a las asociaciones profesionales en las que desarrollan diversas actividades relacionadas con el marketing bibliotecario.

Es evidente que la participación de la IFLA otorga suficiente calidad y valor a esta publicación. Conviene además significar la participación de autores de referencia en el contexto del marketing bibliotecario, tales como Gupta o Webber. Por último, la riqueza que ofrecen los ejemplos y estudios de casos acaecidos en los cinco continentes representa el mayor valor y aportación de esta obra.

\section{Nota}

1. Marketing mix: elemento central de un plan de marketing en el que se definen cuatro aspectos, cuatro "p": el producto (product) y su precio (price), la distribución (place) del mismo y su promoción (promotion).

Viviana Fernández Marcial, Universidad de La Coruña. vivianafm@gmail.com

\section{Suscripciones}

Renovar (o comenzar) la suscripción a "El profesional de la información" es ágil y sencillo.

Usted puede gestionar online su suscripción conectándose a esta web: http://www.elprofesionaldelainformacion.com/suscripciones. html Si lo desea puede comunicar con nosotros dirigiéndose a: suscripciones@elprofesionaldelainformacion.com 